(c) American Dairy Science Association, 2006.

\title{
Pharmacokinetics and Mammary Elimination of Imidocarb in Sheep and Goats
}

\author{
C. Belloli, ${ }^{1}$ O. R. Lai, P. Ormas, C. Zizzadoro, G. Sasso, and G. Crescenzo \\ Department of Animal Health and Welfare, University of Bari, Italy
}

\begin{abstract}
The pharmacokinetics and mammary excretion of imidocarb dipropionate, a therapeutic/prophylactic agent against a variety of tick-borne hemoparasitic diseases in domestic animals, have been investigated in sheep and goats. A commercial formulation of imidocarb dipropionate was injected i.m. at a single dose of $3 \mathrm{mg} /$ $\mathrm{kg}$ of body weight in 7 mature lactating ewes and 8 lactating does in good health. Blood samples were collected for $48 \mathrm{~h}$ after administration and milk samples were collected every $12 \mathrm{~h}$ for $10 \mathrm{~d}$. A weak cation-exchange solid-phase procedure was used to remove imidocarb from plasma. A hexane/isoamyl alcohol liquidliquid procedure was adopted to extract the drug from the milk of sheep. The same method was used for goat milk after exposing the matrices to enzymatic digestion. The extracted samples were analyzed by HPLC. The i.m. disposition kinetics of imidocarb in the 2 species showed significant differences in the rate of elimination $(0.0075 \pm 0.002$ and $0.025 \pm 0.004 \mathrm{~L} / \mathrm{h}$ in sheep and goats, respectively), being faster in ewes than in does. Nevertheless, a smaller area under the concentrationtime curve $(12.21 \pm 0.76$ and $9.49 \pm 0.54 \mu \mathrm{g} / \mathrm{mL}$ per $\mathrm{h}$ in sheep and goats, respectively), a larger volume of distribution $(4.18 \pm 0.44$ and $7.68 \pm 0.57 \mathrm{~L} / \mathrm{kg}$ in sheep and goats, respectively), and a longer mean residence time $(9.07 \pm 0.77$ and $14.75 \pm 2.20 \mathrm{~h}$ in sheep and goats, respectively) were found in goats, suggesting a more rapid and effective drug storage in tissues during the first $48 \mathrm{~h}$ after the injection. The concentrations of imidocarb in milk of both species were higher than in plasma. However, a fast passage through the bloodmilk barrier and a high storage of imidocarb were observed in the milk of ewes, whereas the drug concentrations were not as high nor was the extent of drug penetration from blood to milk as great in the milk of goats $\left(\mathrm{AUC}_{\text {milk 0-48 }} / \mathrm{AUC}_{\text {plasma 0-48 }}=2.5 \pm 0.45\right.$ and $1.26 \pm 0.27$ in sheep and goat, respectively). Despite the differences in pharmacokinetic behavior, and considering the sen-
\end{abstract}

Received October 11, 2005.

Accepted January 18, 2006.

${ }^{1}$ Corresponding author: c.belloli@veterinaria.uniba.it sitivity of pathogens to imidocarb, the same dosage regimen can be used for clinical efficacy against Babesia spp. infection in both species. In contrast, the differences in depletion of imidocarb residue in milk and the large variability in mammary drug elimination found in goats suggests that great care should be taken in defining the withdrawal time in small ruminant dairy species.

Key words: imidocarb, pharmacokinetics, milk residues, small ruminant

\section{INTRODUCTION}

A variety of tick-borne hemoparasitic diseases occurs in small ruminants, and the economic impact of babesiosis, ehrlichiosis, and anaplasmosis is generally considered striking (Uilenberg, 1995). In endemic areas, control and eradication programs for ticks and tick-borne diseases aim at obtaining enzootic stability and optimizing tick-control strategies, husbandry practices, and effective methods of immunization (Nari, 1995). In many regions, the economic impact created by the widespread presence of tick-borne diseases, such as babesiosis, in sheep and goats warrants proper veterinary care. Veterinary practitioners commonly resort to drugs for elimination of parasites from severely affected animals or for protection of animals traveling from diseasefree areas to endemic regions.

Many drugs have been advocated over the years as therapeutic or prophylactic agents against infection with hemoprotozoa in domestic animals, and among them imidocarb (IMD) is considered the most efficacious and safest of all available medications (Knowles et al., 1980; Kuttler, 1980). Imidocarb is a chemotherapeutic agent of the family of carbanilide derivatives [3,3'-bis (2-imidazolin-2-yl)-carbanilide] with antiprotozoal activity. It is usually administered as dipropionate salt and has been used for over $20 \mathrm{yr}$ in the treatment and prophylaxis of some protozoal diseases such as babesiosis and anaplasmosis in food-producing species (Knowles et al., 1980; Kuttler, 1980; WHO, 1999).

The literature indicates that a high and persistent amount of IMD remains in the animal body, a characteristic that has caused some concern for the production of food for human consumption. The reason for this 
prolonged persistence has been ascribed both to 1) the resistance of the drug to biotransformation processes, as reported in in vitro studies on cattle (Coldham et al., 1995) and in vivo studies on sheep (Aliu et al., 1977), and 2) a strong binding of the drug to nuclear components, causing the formation of large deposits (especially in the liver and kidney) that release the molecule very slowly (Coldham et al., 1995; Moore et al., 1996). More recent work (Lai et al., 2002) shows that, after i.m. administration of $3.0 \mathrm{mg} / \mathrm{kg}$ of IMD dipropionate, high and long-lasting drug levels in sheep and goats are found in the liver and kidney, suggesting that these tissues are targets for residues. In contrast, muscles are of negligible importance as storage tissues. Moreover, the high, long-lasting concentrations found in the brain show that the drug is capable of crossing the blood-brain barrier, which raises concern about the potential neurotoxic effects of IMD. In the study, it was observed that goats had lower storage capability than sheep, suggesting differences in depletion time between the 2 species.

In 2003 the European Agency for the Evaluation of Medicinal Products (EMEA) published the conclusions and recommendations of the Committee for Veterinary Medicinal Products (CVMP), with an extension of definitive maximum tolerated residue levels (MRL) for IMD to ovine edible tissue ( $300 \mu \mathrm{g} / \mathrm{kg}$ in muscle, $50 \mu \mathrm{g} /$ $\mathrm{kg}$ in fat, $2,000 \mu \mathrm{g} / \mathrm{kg}$ in liver, $1,500 \mu \mathrm{g} / \mathrm{kg}$ in kidney; CVMP, 2003). To date, however, no MRL values have been fixed for sheep milk, primarily because a validated routine analytical method for the monitoring of IMD residues in ovine milk is not available.

Although sheep and goats are often regarded as closely related species due to similarity in digestive physiology and BW, several studies have reported significant differences between the 2 species in the pharmacokinetics of several chemotherapeutics (Taha et al., 1999). Although this does not necessarily imply that different dosage schedules are needed to guarantee clinical efficacy, it can produce large differences in drug residue depletion.

The aim of this investigation was to examine the pharmacokinetics and residual depletion from milk of a commercial product containing IMD dipropionate in sheep and goats, to provide a more rational and safe use of the drug in small ruminants.

\section{MATERIALS AND METHODS}

\section{Animals}

Seven mature ewes (crossbred, weighing 45 to $75 \mathrm{~kg}$ ) and 7 does (crossbred, weighing 50 to $65 \mathrm{~kg}$ ), in good health based on physical and clinical examination, were used. The animals were in the terminal milking phase and had not received any treatment for several months. Throughout the study, they were housed in open-air pens with straw bedding and free access to water, and were lead to pasture during the day. The diet was integrated with a commercial pelleted food (Lattipecora, Veronesi Mangimi, Verona, Italy) for a ratio of about $2 \% \mathrm{BW}$ divided in 2 daily administrations.

\section{Drug Formulation and Dosing}

A commercial formulation containing a water solution of IMD dipropionate (Carbesia, Schering-Plough s.p.a., Milan, Italy) at the concentration of $121.15 \mathrm{mg} /$ $\mathrm{mL}$ (corresponding to $85 \mathrm{mg}$ of IMD free base) was used. The drug was injected i.m. (thigh muscle) at the single dose of $3.0 \mathrm{mg} / \mathrm{kg}$ of BW corresponding to $2.1 \mathrm{mg}$ of IMD base $/ \mathrm{kg}$ of BW.

\section{Sample Collection}

Blood samples $(10 \mathrm{~mL})$ were collected from the jugular vein in tubes containing EDTA as an anticoagulant (Vacutainer System, Becton Dickinson, Plymouth, UK) at 10, 20, and $30 \mathrm{~min}$ and at $1,2,3,4,5,6,7,8,10$, $12,24,36$, and 48 h after i.m. administration. Plasma was immediately obtained by centrifugation at $1,500 \times$ g. Milk samples $(20 \mathrm{~mL})$ were collected by manual milking every $12 \mathrm{~h}$ for $10 \mathrm{~d}$ from 7 ewes and 7 does. All the samples were stored at $-20^{\circ} \mathrm{C}$ until they were analyzed.

\section{Sample Analysis}

A weak cation-exchange solid-phase extraction procedure described by Tarbin and Shearer (1992), with minor changes, was used to determine the amount of IMD in the plasma of the animals. Briefly, $1 \mathrm{~mL}$ of plasma was passed through solid-phase extraction columns (Supelclean WCX $1 \mathrm{~mL}$; Supelco Inc., Bellefonte, PA) conditioned with $2 \mathrm{~mL}$ of a mixture of methanol (50\%), acetonitrile $(25 \%)$, and trifluoroacetic acid $(0.1 \mathrm{M}$, acetic acid $0.1 M, \mathrm{NaOH} 0.2 M ; 25 \%)$. The cartridge was washed with $2 \mathrm{~mL}$ of water:acetonitrile (90/10, vol/vol) and the analyte was eluted with $3 \mathrm{~mL}$ of acetonitrile:methanol:trifluoroacetic acid (50/45/5, vol/vol/vol). The eluent was evaporated under a nitrogen stream and the residue was then redissolved in $250 \mu \mathrm{L}$ of mobile phase B (0.005 $M$ 1-pentansulfonic acid sodium salt in water containing $0.1 \%$ triethylamine, adjusted to $\mathrm{pH}$ 3.2 with glacial acetic acid) for analysis by HPLC. A previously validated extractive procedure was used to measure IMD in the milk of goats (Crescenzo et al., 2002). The sample ( $2 \mathrm{~mL})$ was enzymatically digested by adding $2 \mathrm{mg}$ of subtilisin in $500 \mu \mathrm{L}$ of PBS, vortexed, and placed in a thermostatic bath at $56^{\circ} \mathrm{C}$ for $1 \mathrm{~h}$. After 
digestion, the sample was made alkaline with $2 \mathrm{~mL}$ of $\mathrm{NaOH}(1 M)$, added with $8 \mathrm{~mL}$ of hexane/isoamyl alcohol (vol/vol, 3:2), ultrasonicated for $20 \mathrm{~min}$ at $40^{\circ} \mathrm{C}$, and centrifuged for $30 \mathrm{~min}$ at $4,500 \times \mathrm{g}$. The collected organic phase was back-extracted in $1 \mathrm{~mL}$ of $\mathrm{HCl}(1 N)$ by vortexing and ultrasonicating for $20 \mathrm{~min}$ at $40^{\circ} \mathrm{C}$, then centrifuging for $30 \mathrm{~min}$ at $4,500 \times \mathrm{g}$. The aqueous phase was filtered through a $0.45-\mu \mathrm{m}$ syringe filter (Chromafil Einmalfilter, $0.45 \mu \mathrm{m} \times 15 \mathrm{~mm}$; Mackery-Nagel, Duren, Germany), and analyzed by HPLC. The same procedures were adopted to extract IMD from the milk samples of ewes, but the enzymatic digestion was not required to obtain acceptable recoveries (Crescenzo et al., 2002).

The HPLC analytical procedure (Beckman Instruments, Inc., Fullerton, CA) was performed by adapting the method described by Gummow et al. (1995); separation was achieved with a $\mathrm{C}_{18}$ reverse-phase column ( $\mathrm{Su}$ pelco $\mathrm{ABZ}^{+}$Plus, $\left.150 \times 4.6 \mathrm{~mm}, 5 \mu \mathrm{m}\right)$ and $\mathrm{UV}$ detection. The mobile phases were acetonitrile (phase A) and $0.005 M$ 1-pentansulfonic acid sodium salt in water with $0.1 \%$ triethylamine, adjusted to $\mathrm{pH} 3.2$ with glacial acetic acid (phase B). The mobile phases were prepared daily, filtered through a $0.45-\mu \mathrm{m}$ filter (phase filtration apparatus with membrane filters, Supelco Inc.), and degassed under vacuum. The analyses were performed at a flow rate of $1 \mathrm{~mL} / \mathrm{min}$ in a linear gradient elution: 0 to 2 min $10 \%$ phase A; 2 to 8 min $20 \%$ phase A; 8 to 12 min $20 \%$ phase A; and 12 to 15 min $10 \%$ phase A. The UV detector was set at $250 \mathrm{~nm}$.

\section{Validation Parameters}

The IMD stock standard solution $(1 \mathrm{mg} / \mathrm{mL})$ was prepared from the IMD dipropionate reference standard (batch no. 400196, Mallinckrodt Veterinary, Verona, Italy), dissolved in water, and stored at $4^{\circ} \mathrm{C}$. The linearity between reference standard concentrations and detector response was determined for 9 concentrations of the IMD dipropionate reference standard (range 0.025 to $10 \mu \mathrm{g} / \mathrm{mL} ; \mathrm{n}=3$ ) by regression analysis (Prism 3.0, GraphPad Software, Inc., San Diego, CA). The accuracy and precision of the method was determined by injecting extracted drug-free matrices spiked with 3 concentrations $(0.25,0.5$, and $1.0 \mu \mathrm{g} / \mathrm{mL})$ in 3 replicates over a 3 -d period. The limits of quantification (LOQ) were determined by injecting extracted drug-free matrices spiked with known concentrations of IMD (3 fortified samples for each matrix) and determining the minimum detectable concentration.

\section{Pharmacokinetic Analysis}

Plasma and milk concentrations for each animal were analyzed using a computer program (WinNonlin vs. 4.1,
Pharsight Co., Mountain View, CA) that provided compartmental and noncompartmental analyses of the experimental data. The pharmacokinetic compartmental analyses of the weighted $\left(y=1 / y^{2}\right)$ experimental data were used to define the absorption $\left(\mathrm{k}_{\mathrm{abs}}\right)$, distribution $(\alpha)$, and elimination $(\beta)$ rate constants as well as the rate constants of transfer from the central to the peripheral $\left(\mathrm{k}_{12}\right)$ and from the peripheral to the central compartment $\left(\mathrm{k}_{21}\right)$. The program provides the least squares estimate of the model parameter using the Gauss-Newton algorithm to minimize the sum of the square residual. The optimal model was determined by application of Akaike's information criterion (Yamaoka et al., 1978). The absorption, distribution, and elimination half-lives ( $\left.\mathrm{t}^{1} / 2 \mathrm{abs}, \mathrm{t}^{1} / 2 \alpha, \mathrm{t}^{1} / 2 \beta\right)$ were calculated as $\ln 2 / \mathrm{k}_{\mathrm{abs}}$, $\ln 2 / \alpha$, and $\ln 2 / \beta$, respectively.

The following pharmacokinetic parameters were derived from the noncompartmental analysis of the raw time concentration data computed by the program: the area under the curve (AUC) calculated by the trapezoidal method from the time of dosing and extrapolated to infinity $\left(\mathrm{AUC}_{\mathrm{inf}}\right)$, the volume of distribution based on the terminal phase corrected for the fraction of the absorbed dose $\left(\mathrm{Vd}_{(\mathrm{area})} / \mathrm{F}\right)$, and the total body clearance corrected for the fraction of the absorbed dose (ClB/ F). Using statistical moments (Riegelman and Collier, 1980), the noncompartmental analysis also provided the mean residence time extrapolated to infinity $\left(\mathrm{MRT}_{\text {inf }}\right)$.

The total elimination of IMD in milk was expressed by the area under the milk drug concentration-time curve from time zero to $144 \mathrm{~h}$ after dosage $\left(\mathrm{AUC}_{\text {milk } 0 \text { - }}\right.$ $144 \mathrm{~h}$ ) and the extent of drug penetration from the blood into the milk was expressed by the ratio of AUC from the time zero to $48 \mathrm{~h}$ after dosing calculated on the drug concentration curve in milk and in plasma $\left(\mathrm{AUC}_{\text {milk }}\right.$ $\left.{ }_{48 \mathrm{~h}} / \mathrm{AUC}_{\text {plasma } 0-48 \mathrm{~h}}\right)$. The elimination rate constants $\left(\mathrm{k}_{\mathrm{el}}\right.$ milk) of IMD in the milk were calculated from the regression analyses of drug concentrations after peak time.

Peak plasma, milk concentrations $\left(\mathrm{C}_{\max }\right)$, and peak times $\left(\mathrm{T}_{\max }\right)$ were expressed as experimental data. Pharmacokinetic variables are expressed as means \pm standard errors. Harmonic means were computed for half-lives and their pseudostandard deviations determined by the jackknife technique according to Lam et al. (1985). The Wilcoxon's Rank Sum test was used to test for significant differences in the half-lives. Differences between means were calculated by Student's unpaired $t$-test

\section{RESULTS}

Imidocarb eluted with a retention time of $9.18 \pm 0.10$ min and the calibration curve of the detector response 
was linear over the selected concentration range (run test: $\left.P>0.05 ; \mathrm{r}^{2}=0.9997\right)$. Under the experimental conditions described, the LOQ was $0.025 \mu \mathrm{g} / \mathrm{mL}$, but considering the concentration factor obtained using the extraction procedures, the actual LOQ for IMD in the plasma and milk of ewes and does was $0.0125 \mu \mathrm{g} / \mathrm{mL}$.

The total recovery obtained was $88.07 \pm 1.34 \%$ for the plasma of ewes and $87.67 \pm 2.0 \%$ for the plasma of does, $75.5 \pm 3.31 \%$ for the milk of sheep and $59.6 \pm 3.83 \%$ for the milk of goats. The accuracy of the recoveries, expressed as closeness of agreement between the known added concentrations and the measured concentrations of the analyte in fortified samples always ranged from 9.9 to $14.6 \%$ for plasma samples of both species, from 19.8 to $22.7 \%$ for the milk of ewes and from 35.3 to $40.4 \%$ for the milk of does. The intra- and interassay precisions of the different methods for each analyzed matrix expressed as relative standard deviation were consistently $<10 \%$ (from 1.45 to 7.85 and from 1.90 to $7.60 \%$ for intra- and interassay precision, respectively).

\section{Pharmacokinetics}

After i.m. administration to sheep and goats, imidocarb was rapidly absorbed and was detectable within 10 min in the plasma of all treated animals. A rapid decline in plasma concentration was observed after peak time, reflecting a fast distribution phase followed by slow elimination (Figure 1); detectable concentrations were maintained for $48 \mathrm{~h}$ in 5 out of 7 ewes and in 6 out of 8 does.

Imidocarb plasma concentrations against time data were best described by a 2-compartment open model. The pharmacokinetic parameters obtained for sheep and goats are shown in Table 1.

Similar values were observed for sheep and goats for peak concentration $\left(\mathrm{C}_{\max }, \mathrm{T}_{\max }\right)$, absorption and distribution rate constants $\left(\mathrm{k}_{\mathrm{abs}}, \alpha\right)$, half-lives $\left(\mathrm{t}_{1 / 2 \mathrm{abs}}, \mathrm{t}_{1 / 2 \alpha}\right)$, elimination half-lives $\left(t_{1 / 2 \beta}\right)$, and total body clearance $(\mathrm{ClB} / \mathrm{F})$. However, the elimination rate constant $(\beta)$ was significantly larger in ewes than in does $(P<0.05)$, whereas a significantly smaller area under the concentration-time curve $(P<0.05)$, and subsequently a significantly larger volume of distribution $\left(\mathrm{Vd}_{(\text {area }}\right) / \mathrm{F} ; P<$ 0.01 ), and a longer mean residence time ( $\mathrm{MRT}_{\text {inf }} ; P<$ 0.05 ) were calculated in the does.

\section{Mammary Elimination}

The results obtained from the analysis of the milk samples collected from the treated ewes and does are illustrated in Figure 2. The drug was detectable in the first sample collected from all animals ( $12 \mathrm{~h}$ postinjection), and the mean milk concentrations were always

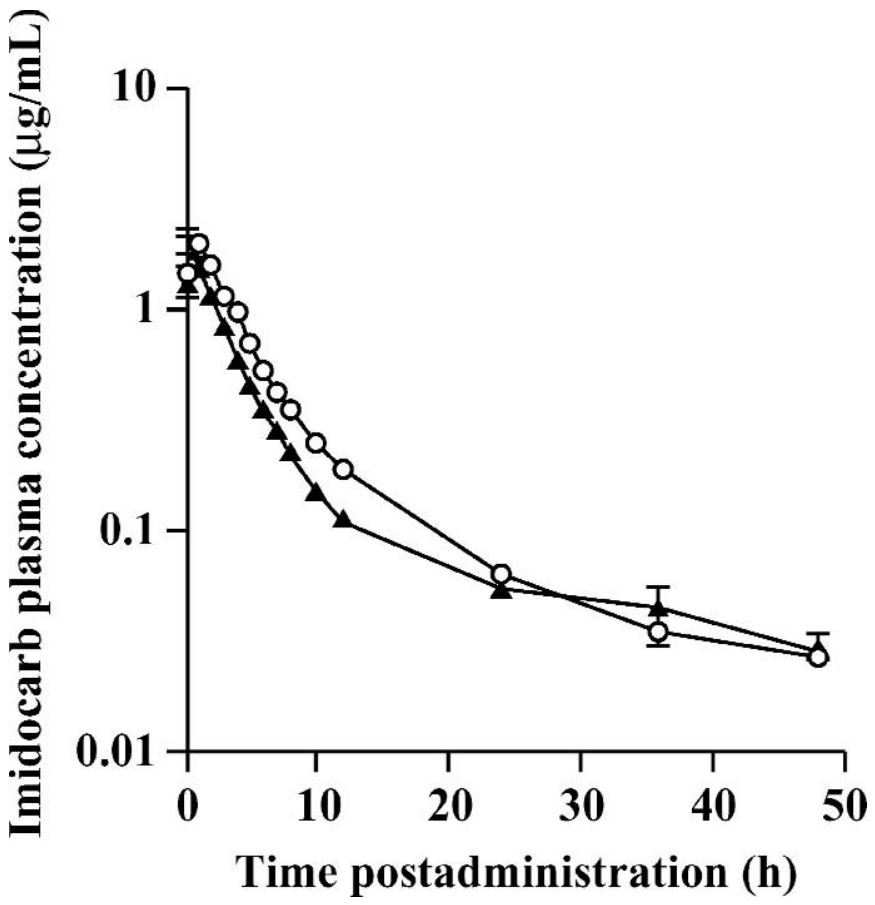

Figure 1. Semilogarithmic plot of the mean plasma concentration to time data of imidocarb after i.m. administration at the dose of 3.0 $\mathrm{mg} / \mathrm{kg}$ of BW as dipropionate salt in sheep $(\bigcirc ; \mathrm{n}=7)$ and goats $(\boldsymbol{\Delta}$; $\mathrm{n}=8)$. Data are expressed as mean $\pm \mathrm{SE}$.

higher than those recorded in the plasma at corresponding times $(P<0.05$; Figure $3 \mathrm{a}, 3 \mathrm{~b})$. From the mean concentration-time profile of IMD in milk, a different drug elimination pattern in ewes and goats was evident. During the first day postinjection IMD concentration in the milk of sheep was higher than that of goats $(P$ $<0.01)$. From the second up to the seventh sampling time (4 d postinjection) the depletion pattern was superimposable in the 2 animal species; after the seventh sampling time, the mean drug levels settled at about double the concentration in the goats compared with the sheep. In the ewes the highest IMD levels (from about 0.50 to $3.80 \mu \mathrm{g} / \mathrm{mL}$ ) were always found on $\mathrm{d} 1$ after the injection, and from the milk elimination curve a fast phase followed by a slow phase was calculated (Table 2). Greater individual variability was detected in IMD mammary elimination in the does and maximum milk concentrations (from 0.12 to $0.80 \mu \mathrm{g} / \mathrm{mL}$ ) were recorded at variable times in the different animals (24 $\mathrm{h}: \mathrm{n}=3 ; 36 \mathrm{~h}: \mathrm{n}=1 ; 48 \mathrm{~h}: \mathrm{n}=1 ; 60 \mathrm{~h}: \mathrm{n}=1,72 \mathrm{~h}: \mathrm{n}=$ 1). Moreover, a clear biphasic elimination pattern was recorded in only 3 of 7 animals. The $\mathrm{AUC}_{\text {milk } 0-48 \mathrm{~h}}$ value calculated in sheep was higher than that calculated in goats $(P<0.01)$ as was the $\mathrm{AUC}_{\text {milk } 0-48 \mathrm{~h}} / \mathrm{AUC}_{\text {plasma } 0-48 \mathrm{~h}}$ ratio $(P<0.05$; Table 2$)$. 
Table 1. Pharmacokinetic parameters (mean $\pm \mathrm{SE})$ of imidocarb in sheep $(\mathrm{n}=7)$ and goats $(\mathrm{n}=8)$ after single i.m. injection at the dose rate of $3.0 \mathrm{mg}$ of dipropionate salt/kg of BW (corresponding to $2.1 \mathrm{mg}$ of base/kg of BW)

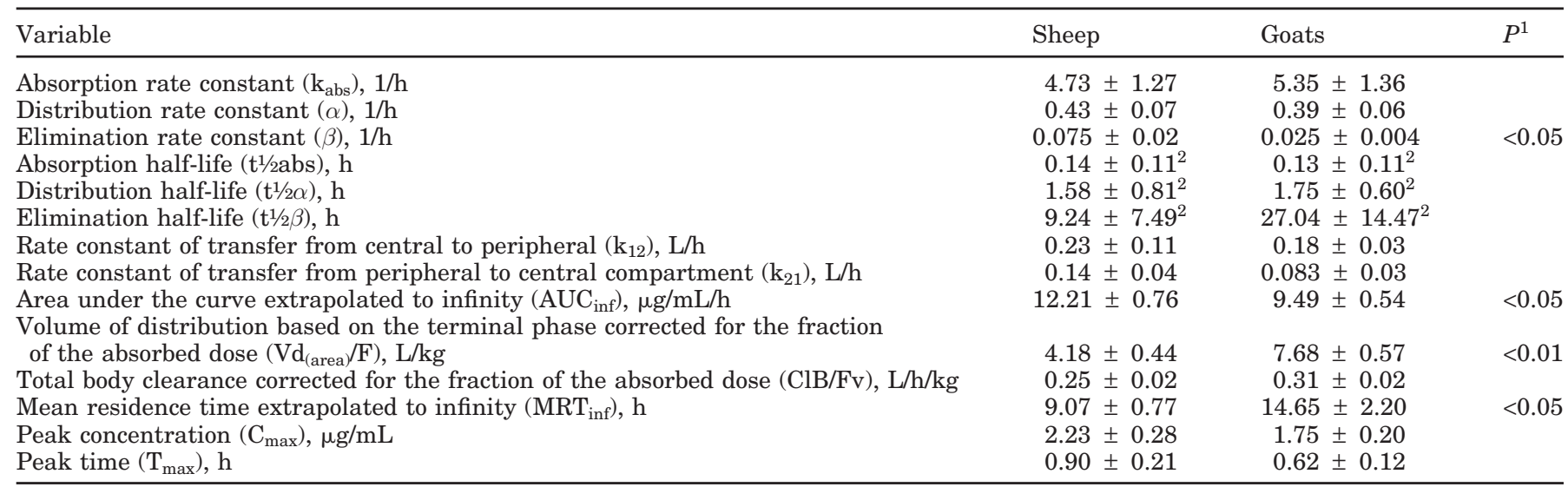

${ }^{1}$ Student's unpaired $t$-test.

${ }^{2}$ Harmonic means \pm pseudostandard deviations.

\section{DISCUSSION}

The validation parameters obtained for the analytical procedures selected to detect IMD in the plasma and milk of sheep and goats are in good agreement with the validation criteria recommended by the European Union (CVMP, 1998), and ensure that these procedures are suitable for the intended purpose.

Imidocarb plasma concentration-time data following i.m. administration in sheep and goats were best fitted to a 2-compartment open model. This is in agreement with previous observations in the horse (Belloli et al., 2002), and describes the typical disposition of an or-

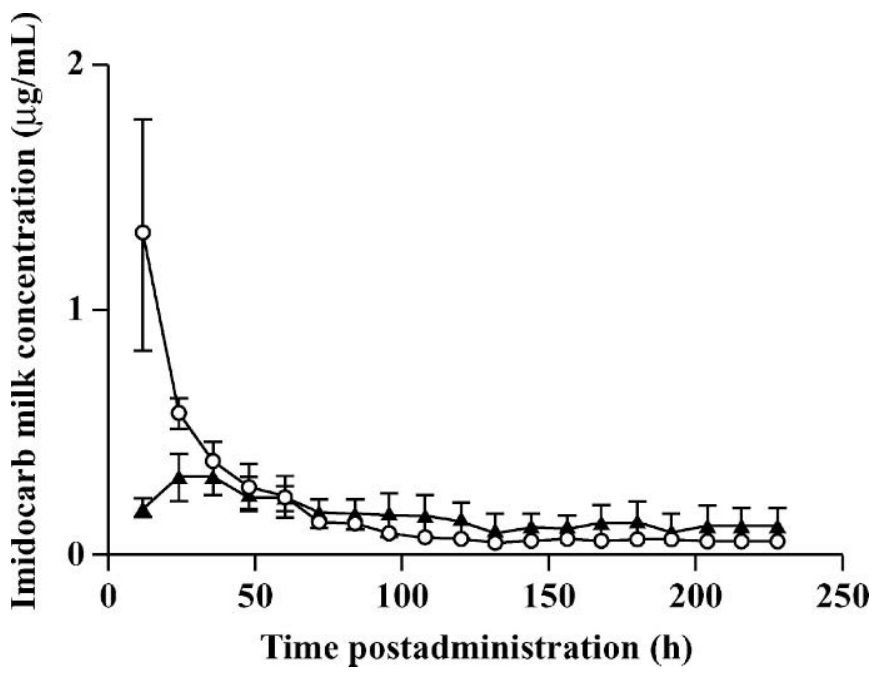

Figure 2. Imidocarb concentration profile in the milk of sheep $(\bigcirc$; $\mathrm{n}=7)$ and goats $(\boldsymbol{\Delta} ; \mathrm{n}=7)$ after i.m. administration at the dose of $3.0 \mathrm{mg} / \mathrm{kg}$ of BW as dipropionate salt. Data are expressed as mean $\pm \mathrm{SE}$. ganic base drug, which, like IMD, shows a great ability to cross cellular membranes, including the blood-brain barrier (Lai et al., 2002). The current data describe fast absorption of the drug and effective distribution to the tissue, providing evidence for a possible sequestration of IMD in extravascular compartments (liver, kidney; Lai et al., 2002) and the need for a prolonged period to complete its elimination. However, a slower absorption $\left(\mathrm{k}_{\mathrm{abs}}=0.92 \pm 0.15 / \mathrm{h}\right)$, and a faster distribution and elimination $(\alpha=4.13 \pm 0.51 / \mathrm{h} ; \beta=0.13 \pm 0.02 / \mathrm{h})$, causing faster kinetics, were observed in the horse (Belloli et al., 2002) compared with small ruminants.

The volume of distribution of IMD indicated extensive distribution of the drug in both species, but more so in goats than in sheep. The recording of a large volume of distribution is not surprising because the intracellular $\mathrm{pH}$ is lower than the extracellular one, causing ionic trapping within the cells for such lipidsoluble basic drugs. Moreover, in ruminants, ionic trapping in the ruminal fluid ( $\mathrm{pH} 5.5$ to 6.5) can further contribute to the large volume of IMD distribution. The results of the studies of IMD depletion in small ruminant tissues (Lai et al., 2002) indicated a higher storage capability in ewes than in does, but a long-lasting storage period ( $30 \mathrm{~d}$ ) was required to reach maximum concentrations in the ewes. On the other hand, the difference between the volume of distribution in the 2 species suggests a more rapid and effective storage of the drug in goats during the first $48 \mathrm{~h}$ after the injection, and is related to the significantly smaller AUC recorded in the goats compared with that recorded in the sheep. This is not related to a slower absorption or a faster elimination of the drug in the goats, because absorption and elimination were equal and even slower than in the ewes, respectively. There are no data on the plasma 

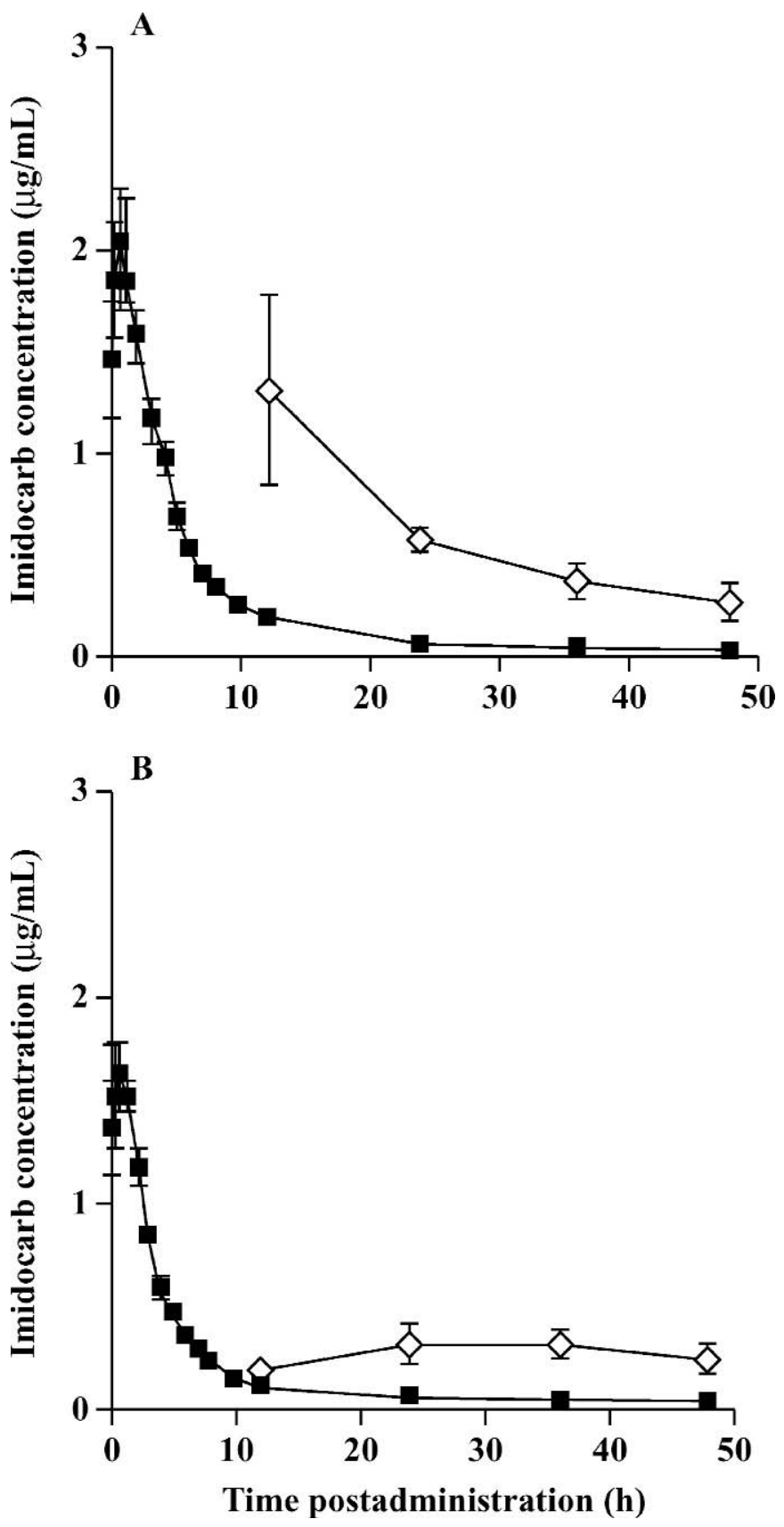

Figure 3. Imidocarb concentration in the plasma (ם) and milk $(\diamond)$ of sheep $(\mathrm{A} ; \mathrm{n}=7)$ and goats $(\mathrm{B} ; \mathrm{n}=7)$ after i.m. administration at the dose of $3.0 \mathrm{mg} / \mathrm{kg}$ of BW as dipropionate salt. Data are expressed as mean $\pm \mathrm{SE}$.

protein binding of IMD in animals, but it probably occurs specifically to $\alpha_{1}$-acid glycoprotein and nonspecifically to albumin as in the case of many basic drugs (Baggot, 2001). Data on the plasma concentration ratio of albumin/glycoprotein show that the amount of glycoprotein is lower in does (albumin/glycoprotein $=6.3$ to 12.6) than in ewes (albumin/glycoprotein $=4.2$ to 7.6 ;
Kaneko et al., 2002), suggesting a smaller fraction of the drug being bound to the protein. This could explain at least partially, the smaller AUC values and the higher volume of distribution observed in this animal species.

Significant differences in the elimination pattern of IMD in ewes' and goats' milk of sheep and goats have been found in this study. The high concentrations of IMD in the milk of ewes during the first day after treatment, and the high $\mathrm{AUC}_{\text {milk } 0-48 \mathrm{~h}} / \mathrm{AUC}_{\text {plasma } 0-48 \mathrm{~h}}$ ratio reflect its fast passage through the blood-milk barrier and a high storage due to the well-known trapping by ionization of the basic drug in milk. Even though the IMD concentration was always higher in the milk of does than in their plasma, drug concentrations that were not high were recorded and the extent of drug penetration from blood to milk was lower. Distinct physiological differences exist between ewes and does in the processes of milk secretion and milk composition (Bergonier et al., 2003). A high SCC characterizes goat milk, and its strong IMD retention, which calls for enzymatic digestion for drug extraction, has been attributed to its strong binding to the cell component (Crescenzo et al., 2002). Thus, lower mammary elimination of IMD in goats can be associated with strong drug binding to mammary tissue.

In dairy animals, mammary excretion of drugs greatly contributes to their total elimination, thus modifying the eliminatory pattern according to different physiological conditions (milking or dry period). In this experimental condition (terminal milking phase) the lower mammary excretion in goats can account for the lower plasma elimination rate constant $(\beta)$ calculated for goats compared with sheep.

Reports on plasma concentrations of IMD that may be effective for therapy or prophylaxis of babesiosis are scarce and not available for the Babesia spp. of small ruminants. Generally, "small" babesia organisms are more refractory to treatment than "large" ones (Kuttler, 1980), though considerable differences in sensitivity are reported for various species of small babesia. An MIC of $0.87 \mu \mathrm{g} / \mathrm{mL}$ was recorded for Babesia bovis, a small babesia (Rodriguez and Trees, 1996), and an MIC of 0.027 to $0.034 \mu \mathrm{g} / \mathrm{mL}$ for Babesia divergens, a large babesia, both isolates of bovine origin (Brasseur et al., 1998). Consequently, despite the different pharmacokinetic behaviors, the IMD plasma concentration profile depicted for sheep and goats and the described effective drug diffusion across cell membranes (Lai et al., 2002) suggest that the therapeutic protocol adopted here may be considered sufficient to guarantee clinical efficacy against the large babesia (Babesia motasi, Babesia crassa) in both species. In contrast, the same cannot be said for the small babesia (Babesia ovis). Moreover, 
Table 2. Selected pharmacokinetic values derived from the analysis of the concentration of imidocarb in the milk of ewes and does after i.m. drug administration at the dose rate of $3.0 \mathrm{mg}$ of dipropionate salt $/ \mathrm{kg}$ of BW (corresponding to $2.1 \mathrm{mg}$ of base $/ \mathrm{kg}$ of BW)

\begin{tabular}{|c|c|c|c|}
\hline Kinetic values & Sheep & Goats & $\begin{array}{l}P^{1} \\
\text { Ewes/does }\end{array}$ \\
\hline Peak concentration $\left(\mathrm{C}_{\max }\right), \mu \mathrm{g} / \mathrm{mL}$ & $1.39 \pm 0.41$ & $0.41 \pm 0.09$ & $<0.05$ \\
\hline Peak time $\left(\mathrm{T}_{\max }\right), \mathrm{h}$ & $18.85 \pm 2.26$ & $41.14 \pm 6.86$ & $<0.05$ \\
\hline Elimination rate constant in milk on $\mathrm{d} 2\left(\mathrm{k}_{\mathrm{el} \mathrm{milk} 2}\right), \mathrm{L} / \mathrm{h}$ & $0.01 \pm 0.001$ & $0.006 \pm 0.001^{2}$ & \\
\hline $\begin{array}{l}\text { Area under the milk drug concentration-time curve (AUC) from } \\
\text { time zero to } 144 \mathrm{~h} \text { after dosage }\left(\mathrm{AUC}_{\text {milk } 0-144}\right), \mu \mathrm{g} / \mathrm{mL} / \mathrm{h}\end{array}$ & $39.45 \pm 5.71$ & $26.43 \pm 8.27$ & \\
\hline
\end{tabular}

${ }^{1}$ Student's unpaired $t$-test.

${ }^{2} \mathrm{n}=3$.

${ }^{3}$ Extent of drug penetration from blood into milk.

the long persistence of IMD in the body, which was shown by the presence of detectable drug concentrations in milk up to $10 \mathrm{~d}$ after the injection, may account for the "reservoir effect" of the drug in the liver and kidney. This may act as a delivery system producing a plasma concentration that is undetectable with the adopted analytical method $(<0.125 \mathrm{mg} / \mathrm{mL})$, but possibly effective in providing the described prophylactic activity (McHardy, 1983).

According to EMEA guidelines that state that the MRL established for cattle could be extrapolated to other ruminant species (CVMP, 1997), the tolerated residual levels for IMD in cattle milk ( $50 \mu \mathrm{g} / \mathrm{kg}$ ) could also be applied to milk of sheep and goats. The results of the depletion of the IMD residue in milk of does and ewes suggest that great care should be taken in defining the withdrawal time in small ruminant dairy species, especially with respect to extrapolating data from cattle. In ewes, as in cattle (WHO, 2003), after a single treatment at the recommended dose of $3.0 \mathrm{mg} / \mathrm{kg}$ of $\mathrm{BW}$, the mean IMD concentration in the milk drops below the MRL defined for bovine milk after $5 \mathrm{~d}$ (10th milking). In contrast, because of the high variability of mammary drug elimination in does, their IMD mean concentrations were above the tolerated limits up to the last sampling, which was $10 \mathrm{~d}$.

It can be concluded that the pharmacokinetics of IMD for the i.m. route differ significantly between sheep and goats. Nevertheless, the same dosage regimen of IMD is applicable to both species for consideration of the sensitivity of the pathogen to IMD. Further investigations should be undertaken to better define the extent to which the variability of mammary elimination of IMD observed in goats can affect the alimentary risk for human consumers.

\section{ACKNOWLEDGMENTS}

The authors wish to thank Luciano Gobbi (Mallinckrodt Veterinary, Verona, Italy) for supplying the imido- carb standard. This investigation was supported by a grant from the Ministry of University and Scientific and Technological Research - 1998.

\section{REFERENCES}

Aliu, Y. O., R. H. Davis, B. J. Camp, and K. L. Kuttler. 1977. Absorption, distribution and excretion of imidocarb dipropionate in sheep. Am. J. Vet. Res. 38:2001-2007.

Baggot, J. D. 2001. Interpretation of changes in drug disposition and interspecies scaling. Pages 92-135 in The Physiological Basis of Veterinary Clinical Pharmacology. J. D. Baggot, ed. Blackwell Science Ltd., Oxford, UK.

Belloli, C., G. Crescenzo, O. R. Lai, V. Carofiglio, O. Marangi, and P. Ormas. 2002. Pharmacokinetics of imidocarb dipropionate in horse after intramuscular administration. Equine Vet. J. 34:625-629.

Bergonier, D., R. de Crémoux, R. Rupp, G. Lagriffoul, and X. Berthelot. 2003. Mastitis of dairy small ruminants. Vet. Res. 34:689-716.

Brasseur, P., S. Lecoublet, N. Kapel, L. Favennec, and J. J. Ballet. 1998. In vitro evaluation of drug susceptibility of Babesia divergens isolated. Antimicrob. Agents Chemother. 42:818-820.

Coldham, N. G., A. S. Moore, M. Dave, P. J. Graham, S. Sivapathasundaram, B. G. Lake, and M. J. Sauer. 1995. Imidocarb residues in edible bovine tissues and in vitro assessment of imidocarb metabolism and cytotoxicity. Drug Metab. Dispos. 23:501-505.

Crescenzo, G., O. R. Lai, C. Belloli, G. Sasso, and P. Ormas. 2002. Validated analytical methods for determination of imidocarb in tissues and milk of cattle, sheep and goats. Ital. J. Food Sci. 14:99-111.

CVMP. 2003. Imidocarb (Extension to sheep). Summary report. EMEA/MRL/881/03-FINAL (www.emea.eu.int). Committee for Medicinal Products for Veterinary Use, European Medicines Agency, London, UK.

CVMP. 1998. Guideline on validation of analytical procedures: Methodology. EMEA/CVMP/VICH/591/98-FINAL (www.emea.eu.int). Committee for Medicinal Products for Veterinary Use, European Medicines Agency, London, UK.

CVMP. 1997. Note for guidance on establishment of maximum residue limits for minor animal species. EMEA/CVMP/153a/97-FINAL (www.emea.eu.int). Committee for Medicinal Products for Veterinary Use, European Medicines Agency, London, UK.

Gummow, B., J. L. Du Preez, and G. E. Swan. 1995. Paired-ion extraction and high-performance liquid chromatographic determination of diminazene in cattle plasma: A modified method. Onderstepoort J. Vet. 62:1-5.

Kaneko, J. J., J. W. Harvey, and M. L. Bruss. 2002. Appendixes VIII. Pages 893-894 in Clinical Biochemistry of Domestic Animals. 5th 
ed. J. J. Kaneko, J. W. Harvey, and M. L. Bruss, ed. Academic Press, London, UK.

Knowles, R. C., J. L. Hurrigan, and A. A. Holbrook. 1980. Equine piroplasmosis. Equine Pract. 2:10-14.

Kuttler, K. L. 1980. Pharmacotherapeutics of drugs used in treatment of anaplasmosis and babesiosis. J. Am. Vet. Med. Assoc. 176:1103-1108.

Lai, O. R., C. Belloli, G. Crescenzo, V. Carofiglio, O. Marangi, P. Cagnardi, and P. Ormas. 2002. Depletion and bioavailability of imidocarb residues in sheep and goat tissues. Vet. Hum. Toxicol. 44:79-83.

Lam, F. C., C. T. Humg, and D. G. Perrier. 1985. Estimation of variance for harmonic mean half-lives. J. Pharmacol. Sci. 74:229-231.

McHardy, N. 1983. The prophylactic activity of imidocarb against tick-transmitted parasitic infections. Pages 247-254 in Veterinary Pharmacology and Toxicology. Y. Ruckebusch, P. L. Toutain and G. D Koritz, ed. MRP Press Ltd., Lancaster, UK.

Moore, A. S., N. G. Coldham, and M. J. Sauer. 1996. A cellular mechanism for imidocarb retention in edible bovine tissues. Toxicol. Lett. 87:61-68.

Nari, A. 1995. Strategies for the control of one-host ticks and relationship with tick-borne diseases in South America. Vet. Parasitol. 57:153-165.

Riegelman, S., and P. Collier. 1980. The application of the statistical moment theory to the evaluation of in vivo dissolution time and absorption time. J. Pharmacokinet. Biopharm. 8:509-534.
Rodriguez, R. I., and A. J. Trees. 1996. In vitro responsiveness of Babesia bovis to imidocarb dipropionate and selection of drugadapted-line. Vet. Parasitol. 62:35-41.

Taha, A. A., H. A. Elsheikh, A. E. Khalafalla, I. A. Osman, and A. S. Abdullah. 1999. Disposition kinetics of tylosin administered intravenously and intramuscularly in Desert sheep and Nubian goats. Vet. J. 158:210-215.

Tarbin, J. A., and G. Shearer. 1992. High-performance liquid chromatographic determination of imidocarb in cattle kidney with cation-exchange clean-up. J. Chromatogr. B. 577:376-381.

Uilenberg, G. 1995. International collaborative research: Significance of tick-borne hemoparasitic disease to world animal health. Vet. Parasitol. 57:19-41.

World Health Organization (WHO). 2003. Evaluation of certain veterinary drug residues in food. Pages 16-19 in 60th report of the Joint FAO/WHO Expert Committee on Food Additives. Technical Report Series, WHO 918. WHO, Geneva, Switzerland.

World Health Organization (WHO). 1999. Evaluation of certain veterinary drug residues in food. Pages 56-66 in 50th report of the Joint FAO/WHO Expert Committee on Food Additives. Technical Report Series, WHO 888. WHO, Geneva, Switzerland.

Yamaoka, K., Y. Tanigawara, T. Nakagawa, and T. Uno. 1978. Application of Akaike's information criterion (AIC) in the evaluation of linear pharmacokinetic equations. J. Pharmacokinet. Biopharm. 6:165-175. 